\title{
An Unusual Neck Mass: Ingested Chicken Bone
}

\author{
Erhan Demirhan, Metin İber, Özlem Yağız, Tolga Kandoğan, İbrahim Çukurova
}

Department of Otorhinolaryngology Head and Neck Surgery, Tepecik Training and Research Hospital, İzmir, Turkey

Background: Foreign bodies in the upper aerodigestive tract are frequently seen in otolaryngological practice, but migration of an ingested foreign body to the neck is a very rare condition.

Case Report: We present a 66-year-old woman admitted to our outpatient department with a painful neck mass. She had a history of emergency department admission 4 months prior with odynophagia after eating chicken meal. A physical examination revealed a painful and hyperemic mass on the left neck. Antibiotherapy did not relieve the patient's symp- toms and signs. A 3-cm linear foreign body was observed in $\mathrm{X}$-ray and computed tomography scans. The symptoms of the patient were relieved after excision of the foreign body. Conclusion: Although it is a rare situation, migration of a foreign body ingested through the aerodigestive tract to the neck should be kept in mind in the differential diagnosis of patients who present with neck masses.

Keywords: Neck mass, chicken bone, foreign body, odynophagia, dysphagia
Foreign body ingestion is commonly seen in children. Although rarely seen in adults, they can cause increased morbidity and mortality rate (1). Delay in diagnosis and treatment of foreign body can result in severe complications as perforation and obstruction. While $80-90 \%$ of foreign bodies that reach the gastrointestinal system are spontaneously eliminated, 10-20\% require a non-surgical approach; $1 \%$ require surgery (1). Patient complaints can vary according to the size and location of the foreign body. Patients that has upper aerodigestive tract foreign body usually present with dyspnea, changing in voice, severe cough attacks, and dysphagia (2). Presentation with a neck mass is not a usual situation. In this paper we reported an unnoticed ingested foreign body which was presented as a neck mass.

\section{CASE PRESENTATION}

A 66-year-old female patient presented to our outpatient department with a painful lump on the left side of her neck that had persisted for one month. On examination, there was no pathological finding but $3 \times 3 \mathrm{~cm}$ sized, hyperemic and ten- der mass in left lateral neck region. There was also no pathological finding in endoscopic examination. Her prior medical history was unremarkable. The complaints were not relieved and a sharp pointed edge became visible on the left side of the neck in follow up examination after antibiotheraphy (amoxicillin+clavulanate) (Figure 1a). The patient's detailed history revealed that she had been admitted to the emergency department 4 months ago with odynophagia after eating chicken meal. She could not remember the details of previous diagnoses or treatments but she reported that endoscopic examination had been also performed and no foreign body had been detected at that time. After that, her symptoms were gradually relieved, and she had no symptom until admission to our clinic with the neck mass. The patient's only complaint was painful lump and she did not describe dysphagia or odynophagia at the time of admittance to our clinic.

The migration of an ingested foreign body to the neck was suspected. X-ray and computed tomography (CT) scan were performed to confirm the diagnosis. The $\mathrm{X}$-ray showed hyperdense pin-like foreign body in the soft tissue of the left neck. (Figure 1b) CT scans of the neck also showed approximately $3 \mathrm{~cm}$

This case has been presented as a poster at the $36^{\text {th }}$ Turkish National Congress of Otorhinolaryngology Diseases and Head - Neck Surgery, 5-9 November 2014, Antalya, Turkey.

Address for Correspondence: Dr. Erhan Demirhan, Department of Otorhinolaryngology Head and Neck Surgery, Tepecik Training and Research Hospital, İzmir, Turkey Phone: +90 (232) 46969 69-1611 e-mail: demirhanerhan@gmail.com

Received: 1 June 2015 Accepted: 21 July 2015 •DOI: 10.5152/balkanmedj.2016.150779

Available at www.balkanmedicaljournal.org

Cite this article as:

Demirhan E, İber M, Yağız Ö, Kandoğan T, Çukurova İ. An unusual neck mass: Ingested chicken bone. Balkan Med J 2016;33:695-7. 

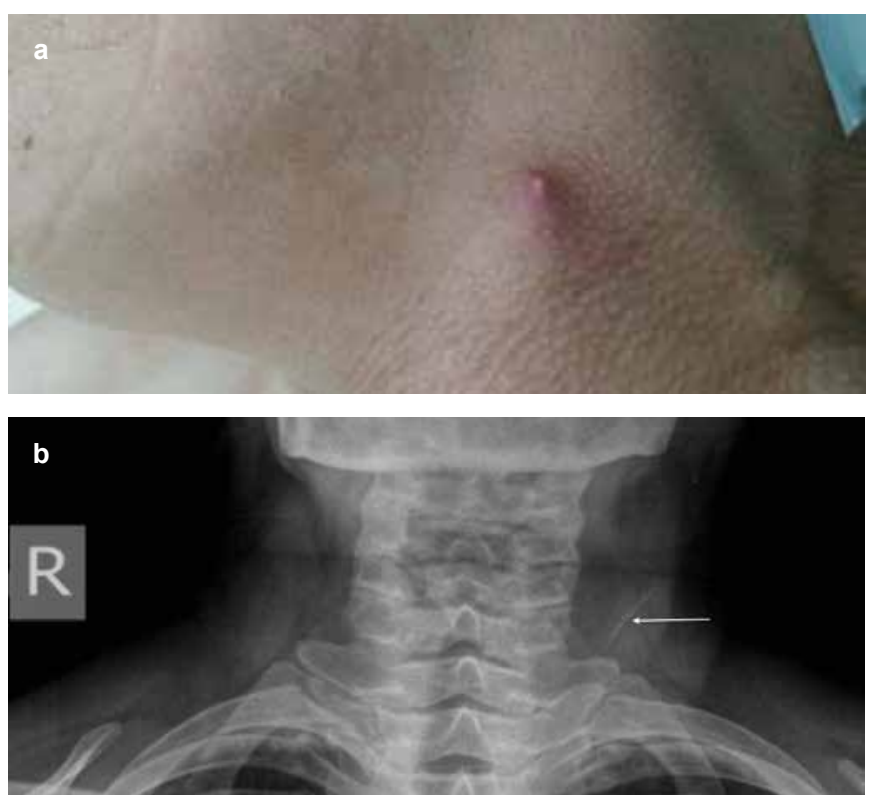

FIG. 1. a,b. Presentation of mass with sharp pointed edge after medical treatment (a) and X-ray view of hyperdense foreign body (arrow) in the soft tissue of the left neck (b)

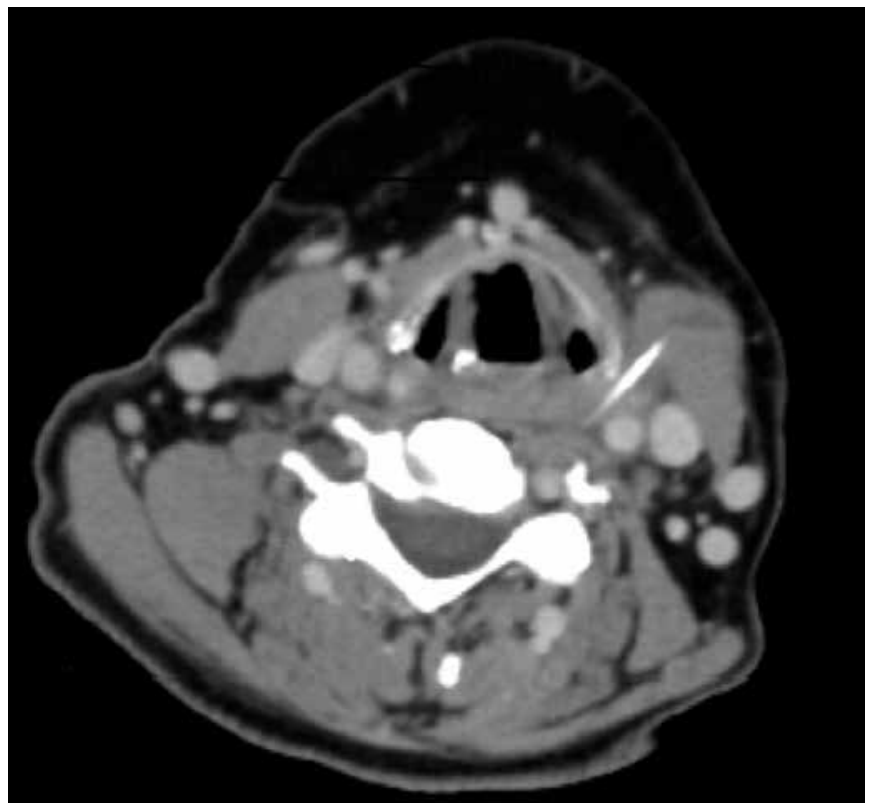

FIG. 2. The close relation between foreign body and carotid artery in CT scan

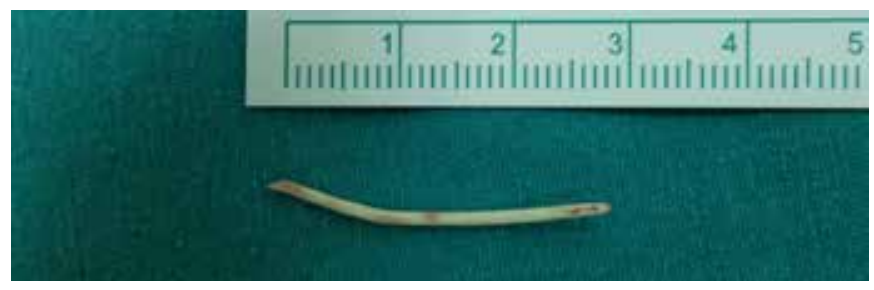

FIG. 3. Removed foreign body (chicken bone) hyperdense foreign body that is close relation with the carotid artery. (Figure 2) Excision was performed under general anesthesia. The chicken bone (distal portion of the chicken fibula) was removed and no complication was observed in the perioperative period. (Figure 3) No hemorrhage or wound infection was observed during the postoperative period, and the patient was discharged at postoperative Day 3. All sutures were removed at postoperative $7^{\text {th }}$ day. The symptoms and signs were fully recovered postoperatively. Written informed consent was taken from the patient.

\section{DISCUSSION}

Foreign bodies of upper aerodigestive tract are frequently seen in the otolaryngological practice. Commonly found objects are fishbones, chicken bones, pieces of glass, dental prostheses, coins, and needles (3-6). Although the majority of small and round objects pass through the gastrointestinal tract spontaneously, sharper and larger objects can lead to serious complications (7).

Migration to the neck of the swallowed foreign body and presentation with cutaneous symptoms are an unusual condition. Patients usually present to the emergency department; foreign bodies are typically diagnosed and removed upon first admission. If the foreign body couldn't be diagnosed at the first admission, catastrophic results can occur including retropharyngeal abscess, mediastinitis, deep neck infection and fatal arteriopharyngeal fistula (7). Chicken fibula has a sharp edge and it can penetrate to the tissues. Complications of sigmoid colon perforation, hepatic abscess and death were reported with ingestion of the chicken bone $(8,9)$. In these reports the foreign body was chicken fibula like in our case. The early diagnosis of an ingested foreign body is important to prevent such complications. In our case, foreign body couldn't be diagnosed at the first time but fortunately no catastrophic complication was observed.

The literature contains a case report on a patient who presented with protrusion of a swallowed fishbone from the skin of the neck (7). In this case, the foreign body also couldn't be detected at the first admission to the emergency department and the diagnosis was delayed. Cutaneous symptoms of that patient manifested 21 days later than first admission. This interval was about 4 months in our case. The migration time through the neck was reported as 1 year for a blunt plastic object (plastic top piece of the knitting needle) in one case report (10). Swallowing, neck motions, tissue reactions, and coughing can facilitate the migration of the foreign body (7). But the time passing from ingestion of the foreign body to having cutaneous manifestation is changing from case to case. 
This difference was probably caused by the slower migration of blunt objects in comparison to sharp objects. So, detailed history is mandatory and past 1 year should be questioned especially for ingestion of blunt foreign bodies.

Consequently, when a patient is admitted with complaints of foreign body ingestion and no foreign body could be detected by endoscopic examination, X-ray should be performed to rule out the presence of a foreign body. CT scans may help to diagnose ingested foreign body and its relationship with vital structures. Also, detailed history should be taken from patients presented with neck mass and unnoticed foreign body should be kept in mind in differential diagnosis.

\section{Ethics Committee Approval: N/A.}

Informed Consent: Written informed consent was obtained from the patient who participated in this case.

Peer-review: Externally peer-reviewed.

Author contributions: Concept - E.D., M.İ., Ö.Y., T.K., İ.Ç.; Design - E.D., M.İ., Ö.Y., T.K., İ.Ç.; Supervision - İ.Ç. E.D.; Data Collection and/or Processing - Ö.Y.; Analysis and/or Interpretation E.D.,M.İ., Ö.Y., T.K.; Literature Search - E.D., Ö.Y.; Writing - E.D.; Critical Reviews - E.D., M.İ., Ö.Y., T.K., İ.Ç.

Conflict of Interest: No conflict of interest was declared by the authors.

Financial Disclosure: The authors declared that this case has received no financial support.

\section{REFERENCES}

1. Lai AT, Chow TL, Lee DT, Kwok SP. Risk factors predicting the development of complications after foreign body ingestion. $\mathrm{Br} J$ Surg 2003;90:1531-5. [CrossRef]

2. Messallam TA. Impacted chicken bone in the laryngopharynx: a case report. Int J Otolaryngol 2011;2011:593504. [CrossRef]

3. Gupta KR, Kakar PK, Saharia PS. Impacted foreign body of retropharyngeal space. J Laryngol Otol 1972;86:519-21. [CrossRef]

4. Okada T, Sasaki F, Todo S. Perforation of the piriform recessus by swallowed glass splinter presenting as pneumomediastinum in a child. Pediatr Surg Int 2004;20:643-5. [CrossRef]

5. Poluri A, Singh B, Sperling N, Har-El G, Lucente FE. Retropharyngeal abscess secondary to penetrating foreign bodies. $J$ Craniomaxillofac Surg 2000;28:243-6. [CrossRef]

6. Dubey SP, Banerjee SB, Ghosh LM. Pharyngeal perforation by swallowed sewing needle. Eur Arch Otorhinolaryngol 2000;257:462-3. [CrossRef]

7. Cheng YC, Lee WC, Kuo LC, Chen CW, Lin HL. Protrusion of a migrated fish bone in the neck. Am J Otolaryngol 2009;30:2035. [CrossRef]

8. Terrace JD, Samuel J, Robertson JH, Wilson RG, Anderson DN. Chicken or the leg: Sigmoid colon perforation by ingested poultry fibula proximal to an occult malignancy. Int $J$ Surg Case Rep 2013;4:945-7. [CrossRef]

9. Byard RW, Gilbert JD. Hepatic abscess formation and unexpected death: a delayed complication of occult intraabdominal foreign body. Am J Forensic Med Pathol 2001;22:88-91. [CrossRef]

10. Ozturk K, Turhal G, Gode S, Yavuzer A. Migration of swallowed blunt foreign body to the neck. Case Rep Otolaryngol 2014;2014:646785. [CrossRef] 